\title{
SYNTHESIS, CHARACTERIZATION AND THERMAL BEHAVIOUR OF SOLID-STATE COMPOUNDS OF BENZOATES WITH SOME BIVALENT TRANSITION METAL IONS
}

\author{
Adriano B. Siqueira, Elias Y. Ionashiro, Cláudio T. de Carvalho, Gilbert Bannach, Emanuel C. Rodrigues and Massao \\ Ionashiro* \\ Instituto de Química, Universidade Estadual Paulista, CP 355, 14801-970 Araraquara - SP, Brazil \\ Recebido em 10/11/05; aceito em 25/5/06; publicado na web em 24/10/06
}

\begin{abstract}
Solid-state MBz compounds, where $\mathrm{M}$ stands for bivalent $\mathrm{Mn}, \mathrm{Fe}, \mathrm{Co}, \mathrm{Ni}, \mathrm{Cu}$ and $\mathrm{Zn}$ and $\mathrm{Bz}$ is benzoate, have been synthesized. Simultaneous thermogravimetry and differential thermal analysis (TG-DTA), differential scanning calorimetry (DSC), infrared spectroscopy and complexometry were used to characterize and to study the thermal behaviour of these compounds. The procedure used in the preparation of the compounds via reaction of basic carbonates with benzoic acid is not efficient in eliminating excess acid. However the TG-DTA curves permitted to verify that the binary compounds can be obtained by thermosynthesis, because the benzoic acid can be eliminated before the thermal decomposition of these compounds. The results led to information about the composition, dehydration, thermal stability, thermal decomposition and structure of the isolated compounds. On heating, these compounds decompose in two $\left(\mathrm{Mn}, \mathrm{Co}, \mathrm{Ni}, \mathrm{Zn}\right.$ ) or three ( $\mathrm{Fe}, \mathrm{Cu}$ ) steps with formation of the respective oxide $\left(\mathrm{Mn}_{3} \mathrm{O}_{4}, \mathrm{Fe}_{2} \mathrm{O}_{3}\right.$, $\mathrm{Co}_{3} \mathrm{O}_{4}, \mathrm{NiO}, \mathrm{CuO}$ and $\mathrm{ZnO}$ ) as final residue. The theoretical and experimental spectroscopic studies suggest a covalent bidentate bond between ligand and metallic center.
\end{abstract}

Keywords: bivalent transition metals; benzoate; thermal behaviour.

\section{INTRODUCTION}

Benzoic acid and some of their derivatives have been used as conservant, catalyst precursors polymers, in pharmaceutical industries, beyond other applications. A survey of literature shows that the complexes of rare earth and d-block elements with benzoic acid and some of its derivatives have been investigated in aqueous solutions and in the solid state.

In aqueous solutions, the publications reported the thermodynamics of complexation of lanthanides by some benzoic acid derivatives ${ }^{1}$, the spectroscopic study of trivalent lanthanides with several carboxylic acids including benzoic $\mathrm{acid}^{2}$, the influence of $\mathrm{pH}$, surfactant and synergic agent on the luminescent properties of terbium chelates with benzoic acid derivatives ${ }^{3}$, the thermodynamic of complexation of lanthanides by benzoic and isophthalic acids ${ }^{4}$ and the synthesis, crystal structure and photophysical and magnetic properties of dimeric and polymeric lanthanide complexes with benzoic acid and their derivatives ${ }^{5}$.

In the solid state the publications reported the vibrational and electronic spectroscopic study of lanthanides and effect of sodium on the aromatic system of benzoic acid ${ }^{6}$; the thermal and spectral behaviour on solid compounds of m-methoxybenzoate with rare earth elements ${ }^{7}$; the reaction of bivalent copper, cobalt and nickel with 3-hidroxy-4methoxy and 3-methoxy-4-hidroxybenzoic acids and a structure for these compounds has been proposed on the basis of spectroscopic and thermogravimetric data ${ }^{8}$; the thermal decomposition of thorium salts of benzoic and 4-methoxybenzoic acids in air atmosphere"; the thermal and spectral behaviour on solid compounds of 5-chloro-2methoxybenzoate with rare earth and d-block elements ${ }^{10-13}$; the synthesis and characterization of 2,3-dimethoxybenzoates of heavy lanthanides and yttrium $^{14}$; the thermal studies on solid compounds of phenyl substituted derivates of benzylidenepyruvates with several metal ions ${ }^{15,16}$; the spectral and magnetic studies of 2-chloro-5-nitrobenzoates of rare earth elements ${ }^{17}$ and thermal behaviour of solid state 4-methoxybenzoates of some bivalent transition metal ions ${ }^{18}$.

*e-mail: massaoi@iq.unesp.br
In an endeavour to extend the literature works, the present publication deals with the synthesis of Mn (II), Fe (II), Co (II), Ni (II), $\mathrm{Cu}$ (II) and $\mathrm{Zn}$ (II) benzoates, studied by means of infrared spectroscopy, simultaneous thermogravimetry and differential thermal analysis (TG-DTA), differencial scanning calorimetry (DSC) and other methods of analysis. The results permitted to obtain information concerning the structure, thermal stability and thermal decomposition of these compounds.

\section{EXPERIMENTAL}

The benzoic acid, $\mathrm{C}_{6} \mathrm{H}_{5} \mathrm{COOH}(\mathrm{HBz}) 99.9 \%$ was obtained from MERCK. Hydrated basic carbonates of Mn (II), Co (II), Ni (II), Cu (II) and $\mathrm{Zn}$ (II) were prepared by adding slowly with continuous stirring satured sodium carbonate solution to the corresponding metal chloride or sulphate for copper solutions until total precipitation of the metal ions. The precipitates were washed with distilled water until elimination of chloride or sulphate ions (qualitative test with $\mathrm{AgNO}_{3} / \mathrm{HNO}_{3}$ solution for chloride ions or $\mathrm{BaCl}_{2}$ solution for sulphate ions) and maintained in aqueous suspension.

Solid state $\mathrm{Mn}$ (II), Co (II), Ni (II), Cu (II) and Zn (II) compounds were prepared by mixing the corresponding metal basic carbonates with benzoic acid, in slight excess. The aqueous suspension was heated slowly up to near ebullition, until total neutralization of the respective basic carbonates. The resulting solutions after cooled were maintained in an ice bath to recrystallize the acid in excess and filtered through a Whatman $n^{\circ} 40$ filter paper. Thus, the aqueous solutions of the respective metal benzoates were evaporated to near dryness in a water bath and kept in a desiccator over phosphorous pentoxide. The same procedure to synthesize the iron (II) compound was unsucessful, due to oxidation reaction of $\mathrm{Fe}$ (II) to $\mathrm{Fe}$ (III) during the washing of the precipitate of basic carbonate of Fe (II), even by using solutions and washing water purged with nitrogen gas.

The iron (II) benzoate was synthesized by adding solution of sodium benzoate ( $\mathrm{pH}=9.5$ ) to iron (II) sulphate solution, both purged with nitrogen gas. No precipitate was observed during the addition of sodium 
benzoate; however the precipitation occurred after five day when the solution satured with $\mathrm{N}_{2}$ was maintained in a freezer at about $6{ }^{\circ} \mathrm{C}$.

In the solid-state compounds, metal ions, hydration water and benzoate contents were determined from TG curves. The metal ions were also determined by complexometry with standard EDTA solution ${ }^{19,20}$ after igniting the compounds to the respective oxides and their dissolution in hydrochloric acid solution.

Infrared spectra for sodium benzoate as well as for its metal-ion compounds were run on a Nicolet model Impact 400 FT-IR instrument, within the $4000-400 \mathrm{~cm}^{-1}$ range. The solid samples were pressed into $\mathrm{KBr}$ pellets.

Simultaneous TG-DTA curves were obtained with thermal analysis system model SDT 2960 from TA Instruments. The purge gas was a dry air flow of $100 \mathrm{~mL} \mathrm{~min}^{-1}$. A heating rate of $20^{\circ} \mathrm{C} \mathrm{min}$ ${ }^{1}$ was adopted with samples weighing about $7 \mathrm{mg}$. Platinum crucibles were used for TG-DTA.

DSC curves were obtained with thermal analysis systems model DSC 25 from Mettler Toledo. The purge gas was a dry air flow of $100 \mathrm{~mL} \mathrm{~min}{ }^{-1}$. A heating rate of $20^{\circ} \mathrm{C} \mathrm{min}^{-1}$ was adopted with samples weighing about $5 \mathrm{mg}$. Aluminium crucibles, with perforated cover, were used for DSC.

\section{Computational strategy}

Calculation of theoretical infrared spectrum of nickel benzoate has been necessary to evaluate the structure and wave function computed by the ab initio SCF Hartree-Fock-Roothan method ${ }^{21}$ using a split valence (3-21g) basis set ${ }^{22,23}$. The performed molecular calculations in this work were done by using the Gaussian 98 routine ${ }^{23}$ and the hardware IBM power 3 . The geometry optimization was carried out without any constraints. The molecule of benzoate contains rings with conformational flexibility, and all variables optimized. The optimization proceeded more uniformly when all variables were optimized.

\section{RESULTS AND DISCUSSION}

Preliminary studies based on TG-DTA curves and infrared spectra, permitted to verify that the synthesized compounds, except iron, were obtained contaminated. The TG-DTA curves also show that the contamination is evolved before the thermal decomposition of the binary compounds. Thus, sample of these compounds were heated in a long test glass tube, and dehydration for manganese and nickel compounds and sublimation for all the compounds were observed. The sublimated material was identified as benzoic acid, m.p. $121{ }^{\circ} \mathrm{C}$ (found); $122{ }^{\circ} \mathrm{C}$ (literature) ${ }^{24}$.

The presence of benzoic acid in the compounds must be due to the aggregation phenomenon provoked by the increase of the solubility of benzoic acid in benzoate solution, and it is not recrystallized even an ice bath. Therefore, the procedure used to eliminate the acid in excess is not efficient. This behaviour had already been observed in the 3-methoxybenzoate of the same metal ions, except copper compound ${ }^{25}$.

Therefore these compounds were heated up to $260(\mathrm{Mn}), 140$ (Co), $230(\mathrm{Ni}), 210(\mathrm{Cu})$ and $140{ }^{\circ} \mathrm{C}(\mathrm{Zn})$, as indicated by the TG-DTA curves and so to obtain binary compounds free from benzoic acid.

Infrared spectroscopic data on benzoate and their compounds with bivalent ions considered in this work are shown in Table 1. The investigation was focused mainly within $1700-1400 \mathrm{~cm}^{-1}$ range because this region is potentially most informative to assign coordination sites. In sodium benzoate, strong band at $1551 \mathrm{~cm}^{-1}$ and a medium intensity band located $1414 \mathrm{~cm}^{-1}$ are attributed to the anti-symmetrical and symmetrical frequencies of the carboxylate groups, respectively ${ }^{6}$. In all the compounds considered in this work the symmetrical and anti-symmetrical vibrations of the $\mathrm{COO}^{-}$groups when compared with the sodium salt, suggesting that the compounds have a covalent bidentate bond.

Table 1. Spectroscopic data for sodium benzoate and compounds with some bivalent metal ions. IR spectra $/ \mathrm{cm}^{-1}$

\begin{tabular}{lccc}
\hline Compound & $v_{(\mathrm{O}-\mathrm{H})} \mathrm{H}_{2} \mathrm{O}^{\mathrm{b}}$ & $v_{\text {sym }(\mathrm{COO})^{-\mathrm{c}}}$ & $v_{\text {asym }(\mathrm{COO})^{-\mathrm{c}}}$ \\
\hline $\mathrm{NaBz}$ & - & $1414_{\mathrm{m}}$ & $1551_{\mathrm{s}}$ \\
$\mathrm{Mn}(\mathrm{Bz})_{2} \cdot$ & - & $1410_{\mathrm{m}}$ & $1533_{\mathrm{s}}$ \\
$\mathrm{Fe}(\mathrm{Bz})_{2} \cdot 0.5 \mathrm{H}_{2} \mathrm{O}$ & $3420_{\mathrm{br}}$ & $1410_{\mathrm{m}}$ & $1549_{\mathrm{s}}$ \\
$\mathrm{Co}(\mathrm{Bz})_{2}$ & - & $1433_{\mathrm{m}}$ & $1541_{\mathrm{s}}$ \\
$\mathrm{Ni}(\mathrm{Bz})_{2} \cdot$ & - & $1435_{\mathrm{m}}$ & $1552_{\mathrm{s}}$ \\
$\mathrm{Cu}(\mathrm{Bz})_{2}$ & - & $1408_{\mathrm{m}}$ & $1562_{\mathrm{s}}$ \\
$\mathrm{Zn}(\mathrm{Bz})_{2}$ & - & $1410_{\mathrm{m}}$ & $1549_{\mathrm{s}}$ \\
\hline
\end{tabular}

${ }^{\mathrm{a}}$ br - broad; w- weak; m- medium; s-strong; ${ }^{\mathrm{b}} \mathrm{v}_{(\mathrm{O}-\mathrm{H})}$ : hydroxyl group stretching frequency; ${ }^{\mathrm{c}} \mathrm{v}_{\mathrm{sym}(\mathrm{COO})}$ and $\mathrm{v}_{\text {asym (COO) }}$ : symmetrical and antisymmetrical vibrations of the $\mathrm{COO}^{-}$group, respectively

The theoretical infrared spectrum of the $\mathrm{Ni}(\mathrm{Bz})_{2}$ was calculated by the using an harmonic field ${ }^{27}$ and the obtained frequencies were not scaled. The geometry optimization was computed by the optimized algorithm of Berny ${ }^{27}$. The obtained geometry from calculations is presented in Table 2.

Table 2. Theoretical geometries parameters of $\mathrm{Ni}(\mathrm{Bz})_{2}$ compound

\begin{tabular}{|c|c|c|}
\hline d & $\mathrm{Ni}-\mathrm{O}_{\mathrm{COO}}$ & $1,92 \AA$ \\
\hline d & $\mathrm{C}_{\mathrm{COO}}{ }^{-}-\mathrm{O}_{\mathrm{COO}}{ }^{-}$ & $1.28 \AA$ \\
\hline d & $\mathrm{C}_{\mathrm{COO}}^{\mathrm{COO}}-\mathrm{C}_{\text {ring }}^{\mathrm{COO}}$ & $1.47 \AA$ \\
\hline d & $\mathrm{C}_{\text {ring }}^{\mathrm{COO}}-\mathrm{C}_{\text {ring }}^{\text {ring }}$ & $1.39 \AA$ \\
\hline d & $\mathrm{C}_{\text {ring }}^{\text {rimg }}-\mathrm{H}_{\text {ring }}^{\text {ring }}$ & $1.07 \AA$ \\
\hline$<$ & $\mathrm{O}_{\mathrm{COO}}^{-}-\mathrm{C}_{\mathrm{COO}}-\mathrm{O}_{\mathrm{COO}}$ & $114.14^{\circ}$ \\
\hline$<$ & $\mathrm{O}_{\mathrm{COO}}^{-}-\mathrm{Ni}-\mathrm{O}_{\mathrm{COO}}$ & $68.04^{\circ}$ \\
\hline$<$ & $\mathrm{C}_{\text {ring }}-\mathrm{C}_{\text {ring }}-\mathrm{C}_{\text {ring }}$ & $119.84^{\circ}$ \\
\hline
\end{tabular}

Key: $\mathrm{Ni}=$ Nickel; $\mathrm{Bz}=$ benzoate $; \mathrm{d}=$ atoms distance $;<=$ atoms angle; $\mathrm{COO}^{-}=$carboxylate; ring $=$benzene ring

The theoretical infrared spectrum of the $\mathrm{Ni}(\mathrm{Bz})_{2}$ (electronic state ${ }^{1} \mathrm{~A}$ ) was obtained with frequency values $\left(\mathrm{cm}^{-1}\right)$, relative intensities, assignments and description of vibrational modes. The theorical frequency, assignments and description was visualized by using graphic software Molden 4.2 for Linux ${ }^{28}$. It was compared with the experimental infrared spectrum of the $\mathrm{NiBz}_{2}$

A comparative analysis between the experimental and theoretical spectrum permitted to verify that: (a) the first assignment shows a strong contribution at $1552 \mathrm{~cm}^{-1}$ suggesting a $v_{\text {asym }}\left(\mathrm{COO}^{-}\right)$assignment, while the theoretical results show the corresponding peak at 1562 $\mathrm{cm}^{-1}$ with discrepancies of $0.64 \%$; (b) the second assignment shows a strong contribution at $1435 \mathrm{~cm}^{-1}$ suggesting a $v_{\mathrm{sym}}\left(\mathrm{COO}^{-}\right)$ assignment, while the theoretical results show the corresponding peak at $1487 \mathrm{~cm}^{-1}$ with discrepancies of $3.6 \%$. The theoretical and experimental data suggesting that compounds considered in this work have a covalent bidentate bond.

Thus, Table 3 presents the analytical and thermoanalytical (TG) results for the prepared compounds by thermosynthesis exception the iron compound, $\mathrm{Fe}(\mathrm{Bz})_{2} .0 .5 \mathrm{H}_{2} \mathrm{O}$, from which the general formula $\mathrm{M}(\mathrm{Bz})_{2}$ can be established, where $\mathrm{M}=\mathrm{Mn}, \mathrm{Ni}, \mathrm{Co}, \mathrm{Cu}, \mathrm{Zn}$ and $\mathrm{Bz}=$ benzoate.

The thermal behaviour of the compounds is heavily dependent on the nature of the metal ion and so the features of each of these compounds are discussed individually. 
Table 3. Analytical and thermoanalytical (TG) data of the compounds

\begin{tabular}{|c|c|c|c|c|c|c|c|c|}
\hline \multirow[t]{2}{*}{ Compound } & \multicolumn{3}{|c|}{ Metal Oxide $(\%)$} & \multicolumn{2}{|c|}{$\Delta \mathrm{Bz}(\%)$} & \multicolumn{2}{|c|}{$\mathrm{H}_{2} \mathrm{O}(\%)$} & \multirow{2}{*}{$\begin{array}{c}\text { Final } \\
\text { Residue }\end{array}$} \\
\hline & Calcd. & TG & EDTA & Calcd. & TG & Calcd. & TG & \\
\hline $\mathrm{Mn}(\mathrm{Bz})_{2}$ & 25.66 & 25.39 & 25.18 & 74.34 & 74.31 & & & $\mathrm{Mn}_{3} \mathrm{O}_{4}$ \\
\hline $\mathrm{Fe}(\mathrm{Bz})_{2} \cdot 0.5 \mathrm{H}_{2} \mathrm{O}$ & 26.00 & 26.16 & 26.19 & 71.06 & 71.20 & 2.93 & 2.75 & $\mathrm{Fe}_{2} \mathrm{O}_{3}$ \\
\hline $\mathrm{Co}(\mathrm{Bz})_{2}$ & 26.65 & 26.74 & 26.83 & 73.35 & 73.26 & - & - & $\mathrm{Co}_{3} \mathrm{O}_{4}$ \\
\hline $\mathrm{Ni}(\mathrm{Bz})_{2}$ & 24.82 & 24.85 & 24.67 & 75.18 & 75.15 & & & $\mathrm{NiO}$ \\
\hline $\mathrm{Cu}(\mathrm{Bz})_{2}$ & 26.01 & 25.99 & 26.17 & 73.99 & 74.01 & - & - & $\mathrm{CuO}$ \\
\hline $\mathrm{Zn}(\mathrm{Bz})_{2}$ & 26.45 & 26.27 & 26.00 & 73.55 & 73.77 & - & - & $\mathrm{ZnO}$ \\
\hline
\end{tabular}

${ }^{a}$ All the residues was confirmed by X-ray powder diffractometry; Key: Bz means benzoate
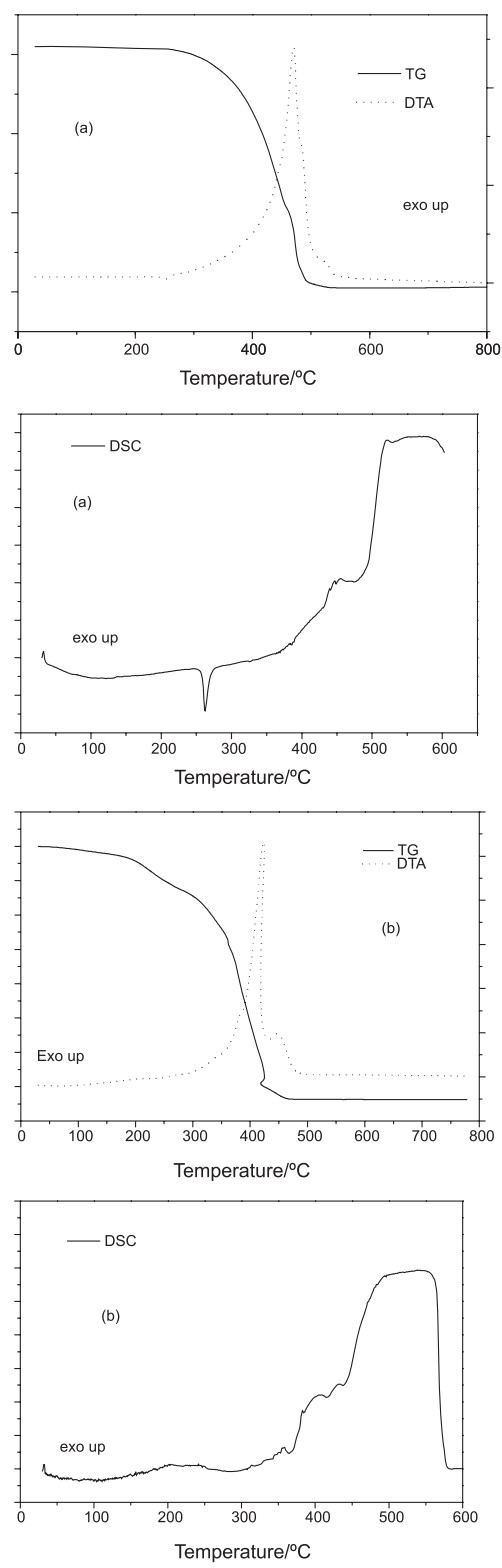

Figure 1. TG-DTA and DSC curves of the compounds: $(a) \mathrm{MnBz}_{2},(b) \mathrm{FeBz}_{2} .0 .5 \mathrm{H}_{2} \mathrm{O},(\mathrm{c}) \mathrm{CoBz}_{2},(\mathrm{~d}) \mathrm{NiBz}_{2},(e) \mathrm{CuBz}_{2},(f) \mathrm{ZnBz}, \mathrm{Bz}=\mathrm{Benzoate}_{2}$

Manganese compound. The TG-DTA and DSC curves are shown in Figure 1(a). The TG curve shows mass losses in two overlapping steps and thermal events corresponding to these losses or physical phenomenon. The small endothermic peak at 260 (DTA) or $265^{\circ} \mathrm{C}$ (DSC) is attributed to the fusion. The mass loss, between 260 and
$500{ }^{\circ} \mathrm{C}$, corresponding to the exothermic peak at 470 (DTA) or 440 and $>500{ }^{\circ} \mathrm{C}$ (DSC) is attributed to the oxidation of organic matter. The total mass loss up to $500{ }^{\circ} \mathrm{C}$ is in agreement with the formation of $\mathrm{Mn}_{3} \mathrm{O}_{4}$, as final residue $(\mathrm{Calcd}=74.34 \%$; $\mathrm{TG}=74.31 \%$ ).

Iron compound. The TG-DTA and DSC curves are shown in 
Figure 1(b). These curves show mass losses in three steps between 60 and $470{ }^{\circ} \mathrm{C}$ and thermal events corresponding to these losses. The first mass loss observed between $60-172^{\circ} \mathrm{C}$ is due to dehydration with loss of $1 \mathrm{H}_{2} \mathrm{O}(\mathrm{Calcd}=2.93 \%$; $\mathrm{TG}=2.75 \%)$; as the dehydration occurs through a slow process, the absorbed heat in this step is probably not enough to produce the endothermic peak. The thermal decomposition of the anhydrous compound occurs in two steps between $172-275^{\circ} \mathrm{C}$, and $275-470^{\circ} \mathrm{C}$, with losses of 9.66 and $61.39 \%$, respectively, corresponding to the exothermic peaks at 423.5 and $448{ }^{\circ} \mathrm{C}$. The profiles of the TG and DTA curves, in the last step show that the oxidation of organic matter is accompanied by combustion. The total mass loss up to $470{ }^{\circ} \mathrm{C}$ is in agreement with the formation of $\mathrm{Fe}_{2} \mathrm{O}_{3}$, as final residue (Calcd. $=73.99 \%$; TG. $=$ $73.81 \%)$.

Cobalt compound. The TG-DTA and DSC curves are shown in Figure 1(c). The TG curve also shows that the thermal decomposition occurs in two overlapping steps, and thermal events due to these losses or physical phenomenon. The endothermic peaks at 275 and $295{ }^{\circ} \mathrm{C}$ (DSC) are attributed to fusion and evaporation of the compound, respectively. The mass loss between 300 and $480{ }^{\circ} \mathrm{C}$, corresponding to the exothermic peak at $480{ }^{\circ} \mathrm{C}$ (DTA) or the exotherm with three peaks at 430,480 , and $590^{\circ} \mathrm{C}$ (DSC) is ascribed to the oxidation of organic matter. The profile of the TG-DTA curves in this step show that the oxidation of the organic matter occurs with combustion. The total mass loss up to $480{ }^{\circ} \mathrm{C}$ is in agreement with the formation of $\mathrm{Co}_{3} \mathrm{O}_{4}$, as final residue $(\mathrm{Calcd}=73.35 \%$; TG $=73.26 \%$ ).

Nickel compound. The TG-DTA and DSC curves are shown in Figure 1(d). These curves show mass losses in two overlapping steps and thermal events corresponding to these losses. The mass loss, between 230 and $440{ }^{\circ} \mathrm{C}$, corresponding to the exothermic peak at $440{ }^{\circ} \mathrm{C}$ (DTA) and several thermal events between 300 and $550{ }^{\circ} \mathrm{C}$ (DSC) are attributed to the oxidation of the organic matter. The profiles of the TG-DTA curves in this step also show that the oxidation of the organic matter occurs with combustion. The total mass loss up to $440{ }^{\circ} \mathrm{C}$ is in agreement with the formation of $\mathrm{NiO}$, as final residue $($ Calcd $=75.18 \%$; $\mathrm{TG}=75.15 \%)$.

Copper compound. The TG-DTA and DSC curves are shown in Figure 1(e). These curves show that the cooper compound is stable up to $280{ }^{\circ} \mathrm{C}$ and above this temperature up to $400{ }^{\circ} \mathrm{C}$, the TG curve shows that the mass loss occurs in three overlapping steps, being the first one corresponding to the sharp endothermic peak at around $295{ }^{\circ} \mathrm{C}$ (DTA, DSC) attributed to the presence of both unreacted copper benzoate and degradation products and this temperature represents the melting point of the compound when assessed in an oxidative atmosphere. The last two steps corresponding to the exotherm with the peaks at 385 and $400{ }^{\circ} \mathrm{C}$ (DTA) or the exotherm between 370 and $550{ }^{\circ} \mathrm{C}$ (DSC) is ascribed to the oxidation of the organic matter. In the last step the TG-DTA also show that the oxidation occurs with combustion. The total mass loss up to $400{ }^{\circ} \mathrm{C}$ is in agreement with the formation of $\mathrm{CuO}$ as final residue (Calcd. $=73.99 \%)$; $\mathrm{TG}=74.01 \%$ ).

Zinc compound. The TG-DTA and DSC curves are shown in Figure 1(f). The mass loss that occurs between 280 and $550{ }^{\circ} \mathrm{C}$, corresponding to the exothermic peak at $520{ }^{\circ} \mathrm{C}$ (DTA) or $525{ }^{\circ} \mathrm{C}$ (DSC) is attributed to the oxidation of organic matter. The endothermic peak at $325^{\circ} \mathrm{C}$ (DTA) is due to the fusion accompanied by thermal decomposition and the endothermic peak at $340{ }^{\circ} \mathrm{C}$ (DSC) is due to the fusion without thermal decomposition. This disagreement is because the DSC and the TG-DTA curves were not obtained in the same conditions. The total mass loss up to $550{ }^{\circ} \mathrm{C}$ is in agreement with the formation of $\mathrm{ZnO}$ as final residue (Calcd. $=73.55 \%$; $\mathrm{TG}=73.77 \%)$.

\section{CONCLUSION}

The TG-DTA curves, infrared spectra and chemical analysis, permitted to verify the presence of benzoic acid in all the synthesized compounds, showing that the procedure used to eliminate the benzoic acid in excess is not efficient.

The TG-DTA, also permitted to verify that the binary compounds can be obtained by thermosynthesis, because the benzoic acid is eliminated before the thermal decomposition of these compounds.

The theoretical and experimental infrared spectroscopic data suggest that the benzoate acts as a bidentate ligand towards the metal ions considered in this work.

The TG-DTA and DSC provided previously unreported information about the thermal stability and thermal decomposition of these compounds.

\section{ACKNOWLEDGEMENTS}

The authors thank FAPESP, CNPq and CAPES Foundations (Brazil) for financial support and computational facilities of IQUNESP and CENAPAD-UNICAMP.

\section{REFERENCES}

1. Yun, S. J.; Kang, S. K.; Yun, S. S.; Thermochim. Acta 1999, 331, 13.

2. Wang, Z. M.; van de Burgt, L. J.; Choppin, G. R.; Inorg. Chim. Acta 1999, 293, 167.

3. Arnaud, N.; Georges J.; Analyst 2000, 125, 1487.

4. Choppin, G. R.; Bertrand P. A.; Hasegawa, Y.; Rizalla, N.; Inorg. Chem. 1982, 21, 3722 .

5. Lam, A. W. H.; Wang, W. T.; Gao, S.; Wen, G.; Zhang, X. X.; Eur. J. Inorg. Chem. 2003, 1, 149 .

6. Lewandowski, W.; Baranska, H.; J. Raman Spectrosc. 1986, 17, 17.

7. Makushova, G. N.; Pirkes, S. B.; Russ. J. Inorg. Chem. 1987, 32, 876.

8. Glowiak, T.; Kozlowski, H.; Erre, L. S.; Gulinati, B.; Micera, G.; Pozzi A.; Brunni, S.; J. Coord. Chem. 1992, 25, 75

9. Brzyska, W.; Karasinski, S.; J. Therm. Anal. 1993, 39, 429.

10. Ferenc, W.; Bocian, B.; J. Therm. Anal. Cal. 2000, 831, 62.

11. Bocian , B.; Czajka, B.; Ferenc, W.; J. Therm. Anal. Calorim. 2001, 66, 729.

12. Czajka, B.; Bocian, B.; Ferenc, W.; J. Therm. Anal. Calorim. 2002, 67, 631 .

13. Ferenc, W.; Bocian, B.; J. Therm. Anal. Calorim. 2003, 74, 521.

14. Ferenc, W.; Walkow-Dziewulska, A.; J. Therm. Anal. Calorim. 2003, 71, 375.

15. Fernandes, N. S.; Carvalho Filho, M. A. S.; Melios, C. B.; Ionashiro, M.; J. Therm. Anal. Calorim. 2003, 73, 307.

16. Fernandes, N. S.; Carvalho Filho, M. A. S.; Mendes, R. A.; Melios, C. B.; Ionashiro, M.; J. Therm. Anal. Calorim. 2004, 76, 193.

17. Ferenc, W.; Bocian B.; Walków-Dziewulska, A.; J. Therm. Anal. Cal. 2004, $76,179$.

18. Rodrigues, E. C.; Siqueira, A. B.; Ionashiro, E. Y.; Bannach, G.; Ionashiro, M.; J Therm. Anal. Calorim. 2005, 79, 323.

19. Flaschka, H. A.; EDTA Titrations, Pergamon Press: Oxford, 1964.

20. De Oliveira, C. N.; Ionashiro, M.; Graner, C. A. F.; Ecl. Quim. 1985, 10, 7 .

21. Roothan, C. C. J.; Rev. Mod. Phys. 1951, 23, 69.

22. Dobbs, K. D.; Hehre, W. J.; J. Comput. Chem. 1987, 8, 861.

23. Dobbs, K. D.; Hehre, W. J.; J. Comput. Chem. 1987, 8, 880.

24. Wendlant, W. W.; Chemical Analysis: Thermal Analysis, $3^{\text {rd }}$ ed., John Wiley \& Sons: New York, Chichester, Brisbane, Toronto, Singapore, 1985, vol. 19, 409.

25. Frisch, M. J.; Trucks, G. W.; Schlegel, H. B.; Scuseria, G. E.; Robb, M. A.; Cheeseman, J. R.; Zakrzewski, V. G.; Montgomery, J. A.; Stratmann, R. E.; Burant, J. C.; Dapprich, S.; Millam, J. M.; Daniels, A. D.; Kudin, K. N.; Strain, M. C.; Farkas, O.; Tomasi, J.; Barone, V.; Cossi, M.; Cammi, R;. Mennucci, B.; Pomelli, C.; Adamo, C.; Clifford, S.; Ochterski, J.; Petersson, G. A.; Ayala, P. Y.; Cui, Q.; Morokuma, K.; Rega, N.; Salvador, P.; Dannenberg, J. J.; Malick, D. K.; Rabuck, A. D.; Raghavachari, K.; Foresman, J. B.; Cioslowski, J.; Ortiz, J. V.; Baboul, A. G.; Stefanov, B. B.; Liu, G.; Liashenko, A.; Piskorz, P.; Komaromi, I.; Gomperts, R.; 
Martin, R. L.; Fox, D. J.; Keith, T.; Al-Laham, M. A.; Peng, C. Y.; Nanayakkara, A.; Challacombe, M.; Gill, P. M. W.; Johnson, B.; Chen, W.; Wong, M. W.; Andres, J. L.; Gonzalez, C.; Head-Gordon, M.; Replogle, E. S.; Gaussian 98, Revision A.11.2, Gaussian, Inc., Pittsburgh PA, 2001.

26. Vallejo, A. C.; Siqueira, A. B.; Rodrigues, E. C.; Ionashiro, E. Y.; Bannach, G.; Ionashiro M.; Ecl. Quim. 2005, 30, 7.
27. Goodson, D. Z.; J. Phys. Chem. 1998, 86, 659.

28. Schelegel, H. B. In New theoretical concepts for understanding organic reaction; Berdron J., ed., Academic: Holanda, 1989, p. 33-53.

29. Schaftenaar, G.; Molden 4.2, CAOS/CAMM Center Nijmegen Toernooiveld: Holanda, 1991. 